\title{
Editorial \\ Exploring the Potentials of Automation in Logistics and Supply Chain Management: Paving the Way for Autonomous Supply Chains
}

\author{
Benjamin Nitsche (D)
}

check for

updates

Citation: Nitsche, B. Exploring the Potentials of Automation in Logistics and Supply Chain Management: Paving the Way for Autonomous Supply Chains. Logistics 2021, 5, 51. https://doi.org/10.3390/ logistics5030051

Received: 20 July 2021

Accepted: 29 July 2021

Published: 3 August 2021

Publisher's Note: MDPI stays neutral with regard to jurisdictional claims in published maps and institutional affiliations.

Copyright: (C) 2021 by the author. Licensee MDPI, Basel, Switzerland. This article is an open access article distributed under the terms and conditions of the Creative Commons Attribution (CC BY) license (https:/ / creativecommons.org/licenses/by/ $4.0 /)$.
Chair of Logistics, Berlin University of Technology, Straße des 17. Juni 135, 10623 Berlin, Germany; nitsche@logistik.tu-berlin.de; Tel.: +49-030-314-26007

\begin{abstract}
The world of logistics is changing and entering a new era. The advance of digitalization and technologization enables new business models, increased process efficiencies, novel planning approaches, and much more but, on the downside, there is also the risk of being lost in the maelstrom of developments. Within these developments, the automation of logistics processes and ultimately the design of autonomous logistics systems is one of the most defining trends that has far-reaching consequences for the planning and execution of future logistics processes. This Special Issue aims to contribute to the discussion and to get to the bottom of the question of how the path towards automated and autonomous logistics systems should be designed. This editorial lays a foundation by presenting application areas of automation and discussing the theoretical path towards autonomous logistics systems. The articles that follow provide highly practical insights into current research results on the automation and autonomization of informational and physical logistics processes.
\end{abstract}

Keywords: process automation; autonomous logistics systems; industry 4.0; logistics 4.0; autonomous driving; internet of things; digital twin; cobots; digitalization

\section{Introduction to Automation in Logistics and Supply Chain Management}

For years, the digital transformation has probably been the most defining trend in the logistics and supply chain industry, presenting practitioners with significant challenges but also offering enormous opportunities to achieve competitive advantages at various levels $[1,2]$. The automation of informational and physical processes represents one of the most significant developments in this regard, as it has the potential to have a lasting impact on the planning and control of logistics systems at the strategic, tactical, and operational levels. The motivations for automating processes are multifaceted and range from the desire to reduce costs and strive for productivity increases to the expectation of more independence regarding the decisions of individuals in logistics networks.

The general idea of automating processes originated from the production environment, where manual processes were supported or replaced by machines in the advancing era of mass production. However, the idea of automation evolved from there and, today, it also includes the automation of informational flows across globally dispersed networks [3]. Therefore, today, automation in the context of logistics and supply chain management includes the automation of physical and also informational flows; each of these is equally important, and there is still room for improvement in each. More specifically, Nitsche et al. define logistics and supply chain automation as "the partial or full replacement or support of a human-performed physical or informational process by a machine. This includes tasks to plan, control or execute the physical flow of goods as well as the corresponding informational and financial flows within the focal firm and with supply chain partners" [4].

Although automation of processes is an important trend for logistics and supply chain management today, and will have increasing importance in the near future, companies are still hesitant and experience challenges in developing automation solutions. In the area 
of automation of physical processes, for example, in warehousing or production logistics, the automation state is more advanced with regard to the automation of informational processes but, even here, high costs and the difficulty of integration into existing systems are still issues. Regarding the automation of informational processes in logistics networks, the complexity even increases, because this often also involves aligning and integrating multiple partners in complex global networks.

Although this had already been an important trend for many years, the COVID-19 pandemic additionally stressed the need for more automation in logistics networks. Straube and Nitsche [5] emphasized the need for more automation to increase responsiveness, and also to gain partial independence from personnel, which was one of the most important trends that logistics and supply chain managers already recognized at the beginning of the pandemic: A trend that manifested and even increased in importance throughout the first year of the pandemic [6]. Many other authors have also stressed that the COVID-19 pandemic eloquently expressed the need for more automation in future supply chains to achieve responsiveness and resilience [7-9].

However, owing to the pressure induced by COVID-19, many promising automation solutions were developed in the short term that proved to be efficient in a wide range of fields. For example, automated emergency response systems have been developed that combine physical and informational automation approaches to automatically supply regions with goods in urgent need [10]. Manufacturing companies, in particular, were quick to develop automation solutions for managing their supply chains more rapidly than would have been the case without the pressure of the pandemic. To give one example, Nitsche and Straube [6] reported that companies developed so-called "supplier risk towers," an automated supplier survey technique that enables greater network visibility through the calculation of vulnerability scores on different levels (supplier, plant, and regional levels). Based on the survey results, this automation solution is a very efficient crisis management approach; however, only a few companies have similar approaches already in place.

Therefore, it can be said that the automation of processes in logistics and supply chain management is advancing rapidly. According to Nitsche and Straube [6], the use of robotic process automation (RPA) will increase within the next five years (by 2026) so that processes will become less error prone and increasingly independent of individuals. Moreover, based on the investigations of Junge et al. [2], it can be assumed that, until 2029, most operational functions in logistics will be handled in near to full autonomy.

Regardless of whether these predictions are accurate, it is already clear that the automation and autonomization of logistics systems is an important trend that is currently gaining in importance. This Special Issue, therefore, aims to contribute to the necessary discussions in selected areas of automation and autonomization. Here, we explain what the path towards autonomous logistics systems can theoretically look like. To this end, the findings of a recent review on application areas and antecedents of automation projects in logistics are first summarized. Subsequently, evolutionary stages towards autonomous systems are briefly explained and the concepts of automation and autonomy are distinguished from each other. Finally, an overview of the content of the articles in this Special Issue is given before heading into the concrete articles.

\section{Paving the Way for Autonomous Supply Chains}

\subsection{Application Areas and Antecedents of Automation in Logistics and Supply Chain Management}

In order to provide an overview of potential application areas of automation as well as the antecedents of successful automation projects, Nitsche et al. [4] conducted a metaanalysis that combined a systematic literature review with a structured group exercise among logistics and supply chain experts. As a result, ten application areas (including multiple sub-areas) were condensed and four dimensions of antecedents (including ten antecedents in total) were defined. The resulting conceptual framework of this study is displayed in Figure 1. 


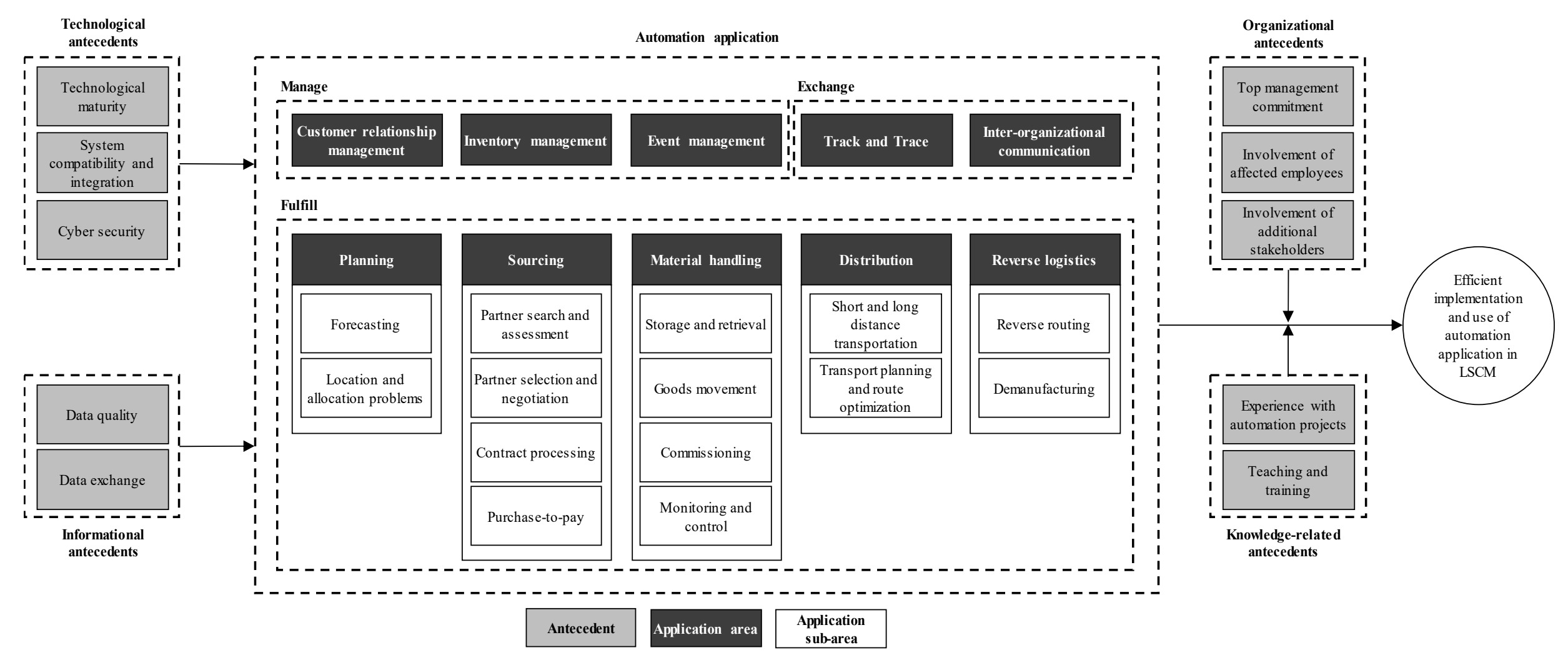

Figure 1. Conceptual framework of automation in logistics and supply chain management [4]. 


\subsubsection{Application Areas of Automation}

As can be seen in Figure 1, the application areas of automation are subdivided into three main dimensions, i.e., fulfill, exchange, and manage. Automation areas belonging to the "fulfill" dimension are automation applications that mainly seek to support the fulfillment of the main customer order process. More specifically, this includes the application areas planning, sourcing, material handling, distribution, and reverse logistics. Of all the application areas surveyed, Nitsche et al. [4] identified the most literature on automation applications in the areas of sourcing and material handling. Although applications in sourcing often aim at the automation of the informational processes of the purchasing department—such as payment processes, partner search, and negotiations-automation applications in material handling mostly include the automation of physical processes through automated and autonomous vehicles and robots. Moreover, in the field of planning, the automation of the forecasting process provides the dominant research field.

Applications related to the "exchange" dimension mostly seek to facilitate the automated collection and exchange of data within the supply chain. More specifically, this includes the automated collection and monitoring of data to improve materials management and also the automated data exchange between supply chain partners through platforms.

Applications in the "manage" dimension mostly focus on management functions indirectly related to the fulfillment process. More specifically, this includes applications from the application areas inventory management, customer relationship management, and event management that range from automated replenishment approaches through automated customer service applications to autonomous multi-agent approaches to automatically identify risks and autonomously change logistics plans accordingly.

On the basis of this very generic classification of application areas of automation in logistics and supply chain management, it can be observed that the field is very broad and includes several substreams of research and literature. Additionally, the classification subdivides automation applications into several areas, although it might be the case that a particular automation application in practice touches several application areas at the same time. Especially when it comes to autonomous logistics systems, where multiple actors communicate and decide autonomously, multiple application areas are being touched upon.

\subsubsection{Antecedents of Automation}

Although the concrete antecedents of an automation application in one of the areas described above might be case specific, analyzing them on a meta level provides certain insights into how to handle the implementation of automation solutions in practice. According to the analysis of Nitsche et al. [4], there are four dimensions of antecedents that influence the efficient implementation and use of automation applications.

"Technological antecedents", including "technological maturity", "system compatibility and integration", as well as "cyber security", in addition to "informational antecedents", including "data quality" as well as "data exchange", have a direct influence on the efficiency of the implementation and use of an automation solution. This means that the technological and also the data-related quality of the solution is of decisive, though not sole, relevance. This in itself is unsurprising, but it does show how complex it is to either purchase or develop a solution that fulfills all these factors, i.e., a solution that is technologically mature, compatible with existing systems, and takes security aspects sufficiently into account, but also that the necessary data for the automation solution is available and can be exchanged. However, there are also other factors that influence the successful implementation. More precisely, "organizational antecedents", including "top management commitment", "involvement of affected employees", as well as "involvement of additional stakeholders", and "knowledge-related antecedents" moderate the effects of technological and informational antecedents. This finding emphasizes that the human factor in the implementation of automation solutions plays a vital role and cannot be neglected. This effect has also been seen with other technology implementations and underlines that automation might enable increases in productivity and reduce dependence of personnel but, more importantly, it is 
still people who plan and steer the project, develop the solution, use the application, etc. This being said, the human factor in automation is also one of the more dominant topics of this Special Issue, in addition to other, equally important discussions.

\subsection{Moving from Automated to Autonomous Processes in Logistics and Supply Chain Management}

The automation of physical and information processes in logistics and supply chain networks is not the end of developments. The vision of not only automating processes, but also gradually equipping them with decision-making powers, and thus enabling those processes to run autonomously, is driving scientists and practitioners and is already a reality in some use cases. Therefore, the step toward automation is to be understood as the next logical step on the way to autonomous logistics systems. Dumitrescu et al. [11,12] proposed five development stages of technical systems towards autonomous systems, which are shown in Figure 2. Although this classification describes the automation and autonomization of technical systems (especially robots, vehicles, and machines, but also software) and would perhaps need further refinement for the purposes of technical processes that are mostly the norm in logistics systems, the classification distinctly shows the necessary evolution of those systems and clearly distinguishes between automated and autonomous systems. The five stages are defined as follows [11,12]:

(1) Remotely controlled systems: For these technical systems, humans take over the major control of the apparatus and no automation or autonomy is present.

(2) Systems with assistance function: For these systems, predefined processes are implemented that seek to assist the user. Although such systems can be argued to be automation applications, all steps of the system are predefined and no intelligent reconfiguration of the system is implemented to react to unforeseen changes.

(3) Semi-automated systems: These systems can perform automated steps in a predefined way and also react to predefined situations with if-then relationships. This means that this is an important intermediate step towards self-learning autonomous systems, but these systems recognize and process events only based on already gained knowledge and not through learning by themselves.

(4) Semi-autonomous systems: These systems are highly automated and efficient and also have self-learning capabilities, while the knowledge base is constantly expanding during ongoing operations. In some cases, these systems can already control themselves and make decisions independently on the basis of the knowledge they have acquired, but human intervention is still necessary in more complex problems.

(5) Autonomous systems: Here, systems have full self-learning capabilities and are able to decide autonomously without human intervention for most situations, even if a particular situation is not known. The system is fully integrated into other relevant systems and can adapt to, but also anticipate, certain events. They run autonomously for longer periods of time and human intervention is sparse.

Even though the concrete assignment of an existing system to one of the levels may not always be possible, undoubtedly, in individual cases, some necessary system characteristics become clear with increasing levels. Whereas automated systems tend to perform predefined, known tasks, autonomous systems are about being equipped with decision-making capabilities and competencies and becoming able to adapt to the situation intelligently. This means that, with increasing level, more complex problems are solvable with less and less human intervention. The ability to make decisions is indispensable for autonomous systems. In the context of logistics, however, this means that owing to the interdisciplinarity and, above all, the high number of stakeholders often involved, the development of autonomous systems that enable running complex logistics processes without human intervention is extremely complex, and their development has not yet reached the level of autonomous technical systems such as autonomous vehicles. The differentiation of the evolutionary stages of autonomous technical processes in logistics on the basis of existing findings is certainly necessary in the context of further research. However, it also makes 
sense to investigate when these evolutionary stages are likely to be reached or when they will become industry-wide practice, and what prerequisites will have to be created for this in logistics.



Figure 2. Development stages of technical systems towards autonomous systems according to Dumitrescu et al. [11] (p. 18).

\section{Summary of Articles in this Special Issue}

\subsection{Scope of Using Autonomous Trucks and Lorries for Parcel Deliveries in Urban Settings}

With urbanization rates increasing at a massive pace, population densities in cities are on the rise and supplying those urban areas with goods in a sustainable manner is becoming more and more challenging. Courier, express, and parcel services (CEP) are taking up this challenge and have to find new methods and approaches to deliver goods faster than ever before. What is already a tough task is further exacerbated by a massive driver shortage in many industrialized countries. Thus, future city logistics is one of the main problems that the industry has to solve. Here, automation and especially autonomous vehicles will play an important role in satisfying the future needs of cities. The authors of this article [13] investigated the future role of autonomous trucks and lorries for parcel deliveries in urban areas. To do that, they investigated current implementation barriers and future delivery opportunities while taking into consideration, through interviews, the views of several actors in the CEP industry. Autonomous delivery concepts were compared to traditional concepts and recommendations were given regarding how autonomous can become advantageous. Additionally, cost implications were discussed and potential use cases were illustrated. With their study, the authors advanced knowledge in this field and triggered important future discussions on what logistics innovations are needed to be better prepared for the future.

\subsection{Cloud and IoT Applications in Material Handling Automation and Intralogistics}

In the wake of digitalization, concepts such as Industry 4.0 have become indispensable and already play a decisive role in the development of new logistics and manufacturing concepts. Especially in the field of logistics automation, material handling in warehouses is often among the first physical processes to be automated by using several technological solutions. Therefore, these physical assets have to be integrated with the digital world, which often leads to problems. Through a literature review, the authors of this article [14] highlighted the main fields of research but concluded that there is a lack of real-world automation applications documented in the literature; to account for that, the authors developed and explained a cloud-based IoT application that could be integrated into a real-life distribution center by using autonomous material handling technologies such as automated guided vehicles, conveyors, shuttles, and others. The case study was situated in a distribution center for home furniture and sporting goods, and they outlined, in 
an impressive way, how beneficial the integration of the cloud-based IoT solution with material handling automation solutions could be. This is a field that will surely receive more attention in practice in the near future.

3.3. A Systematic Review on Technologies for Data-Driven Production Logistics: Their Role from a Holistic and Value Creation Perspective

The automation of informational as well as physical production logistics processes is among the most dominant fields when it comes to automation. In this regard, several datadriven information technologies have arisen that support this development and contribute to the future vision of smart autonomous factories. To add significant value to a necessary discussion in this field, the authors of this article [15] conducted a sound systematic literature review of 142 articles to outline the current state and future role of technologies for data-driven production logistics. By systematically analyzing those articles, first, the authors identify ten technology groups (and multiple technologies belonging to those groups) that enable data-driven production logistics. Subsequently, the identified technologies were mapped to three production logistics activity clusters (shopfloor and operational activities, planning and scheduling-related activities, as well as control and track and trace related activities) and their concrete processes within those clusters. Concrete use cases and the value of the technologies were discussed. Moreover, the authors explained how the technologies surveyed could contribute to value creation in production logistics.

\subsection{Towards Digital Twins of Multimodal Supply Chains}

In several logistics and supply chain trend studies, the development of digital supply chain twins has been identified as among the most important trends in the industry, as it offers new ways for planning, managing, and controlling logistics networks on the basis of up-to-real-time data; however, additional simulation opportunities can also become reality. These new ways of exchanging and processing data also make the digital twin technology a promising one for the automation of informational processes. The authors of this article [16] outlined the necessity of digital twins in future supply chains and dove deeper into the conceptualization of a framework for a holistic digital supply chain twin of multimodal supply chains that seeks to include an entire multimodal supply chain and enables new simulation and evaluation opportunities. The intended approach would also enable early risk detection and mitigation in order to create more robust networks. In this article, the enablers of this digital supply chain twin approach are outlined, the information flow within such multimodal transport chains is investigated, and a framework for a digital supply chain twin application is developed. By doing so, the authors shed light onto an area that will receive more attention in the near future. While digital twins of single assets are already being developed, twins of whole supply chains are still in their early stages. Therefore, discussions and findings such as those in this article are highly relevant.

\subsection{An Analytical Approach for Facility Location for Truck Platooning-A Case Study of an Unmanned Following Truck Platooning System in Japan}

Autonomous and semi-autonomous driving not only plays an important role in the design of future city logistics concepts and last-mile solutions; particularly, in long-distance transport, autonomous concepts can solve safety problems and, at the same time, address the driver shortage that exists in many places. In this context, platooning, one of the main concepts for more efficient long-distance transport, is already being tested in various industrialized countries. The authors of this article [17] investigated the case of truck platooning in Japan and developed a facility location model. By so doing, the authors clearly demonstrated the advantages that platooning can bring as compared with scenarios without this approach. Finding the concrete centers from where multiple unmanned trucks could simultaneously drive in platoons on the same track is a challenging and important task that was addressed by this study. The study outlined the current state of truck platooning in Japan and the developed model was applied to the case of Japan to derive several recommendations for multiple scenarios. 


\subsection{Human Factors Influencing the Implementation of Cobots in High Volume Distribution Centres}

Even if the automation and autonomization of processes in logistics brings various advantages and can give rise to completely new logistics systems, the human factor in this development must not be ignored. On the one hand, it is people who use automation solutions, but, on the other hand, above all, the question arises of what the role of people in logistics systems will be in the future, and when will it be possible to carry out most processes autonomously, i.e., without human intervention, i.e., in a decade or so. In this article [18], the authors put a spotlight on the human factor in logistics in the context of automation. More specifically, they investigated the role of the human factor when implementing cobots for collaborative order picking in high-volume distribution centers. Four in-depth case studies were conducted and analyzed and included multiple interviews with representatives from the case study companies that had already tested and implemented cobots for order picking in their environments. Throughout this process, a multitude of human-related factors were identified that influenced the successful implementation process from project kick-off until actual use. On the basis of this work, recommendations are given for a more human-inclusive approach for implementing such automation solutions while also considering the personal traits of employees.

Funding: This research received no external funding.

Institutional Review Board Statement: Not applicable.

Informed Consent Statement: Not applicable.

Data Availability Statement: Not applicable.

Conflicts of Interest: The author declares no conflict of interest.

\section{References}

1. Kersten, W.; Seiter, M.; von See, B.; Hackius, N.; Maurer, T. Trends and Strategies in Logistics and Supply Chain Management: Digital Transformation Opportunities; DVV Media Group GmbH: Hamburg, Germany, 2017.

2. Junge, A.L.; Verhoeven, P.; Reipert, J.; Mansfeld, M. Pathway of Digital Transformation in Logistics: Best Practice Concepts and Future Developments, Special Edition; Straube, F., Ed.; Scientific Series Logistics at the Berlin Institute of Technology; Universitätsverlag der TU Berlin: Berlin, Germany, 2019; ISBN 978-3-7983-3094-8.

3. Viswanadham, N. The Past, Present, and Future of Supply-Chain Automation. IEEE Robot. Autom. Mag. 2002, 9, 48-56. [CrossRef]

4. Nitsche, B.; Straube, F.; Wirth, M. Application Areas and Antecedents of Automation in Logistics and Supply Chain Management: A Conceptual Framework. Supply Chain Forum Int. J. 2021, 1-17. [CrossRef]

5. Straube, F.; Nitsche, B. Heading into "The New Normal": Potential Development Paths of International Logistics Networks in the Wake of the Coronavirus Pandemic. Int. Transp. 2020, 72, 31-35.

6. Nitsche, B.; Straube, F. Defining the "New Normal" in International Logistics Networks: Lessons Learned and Implications of the COVID-19 Pandemic. WiSt-Wirtsch. Stud. 2021, in press.

7. Wuest, T.; Kusiak, A.; Dai, T.; Tayur, S.R. Impact of COVID-19 on Manufacturing and Supply Networks-The Case for AI-Inspired Digital Transformation. SSRN Electron. J. 2020. [CrossRef]

8. Hobbs, J.E. Food Supply Chain Resilience and the COVID-19 Pandemic: What Have We Learned? Can. J. Agric. Econ. Can. Agroeconomie 2021, 69, 189-196. [CrossRef]

9. Belhadi, A.; Kamble, S.; Jabbour, C.J.C.; Gunasekaran, A.; Ndubisi, N.O.; Venkatesh, M. Manufacturing and Service Supply Chain Resilience to the COVID-19 Outbreak: Lessons Learned from the Automobile and Airline Industries. Technol. Forecast. Soc. Change 2021, 163, 120447. [CrossRef] [PubMed]

10. Khan, I.; Javaid, M. Automated COVID-19 Emergency Response Using Modern Technologies. Apollo Med. 2020, 17, 58-61. [CrossRef]

11. Dumitrescu, R.; Westermann, T.; Falkowski, T. Autonome Systeme in Der Produktion. Ind. 40 Manag. 2018, 2018, 17-20. [CrossRef]

12. Dumitrescu, R.; Gausemeier, J.; Slusallek, P.; Cieslik, S.; Demme, G.; Falkowski, T.; Hoffmann, H.; Kadner, S.; Reinhart, F.; Westermann, T.; et al. Studie "Autonome Systeme"; Studien zum deutschen Innovationssystem; Expertenkommission Forschung und Innovation (EFI): Berlin, Germany, 2018; p. 90.

13. Kassai, E.T.; Azmat, M.; Kummer, S. Scope of Using Autonomous Trucks and Lorries for Parcel Deliveries in Urban Settings. Logistics 2020, 4, 17. [CrossRef]

14. Ponis, S.T.; Efthymiou, O.K. Cloud and IoT Applications in Material Handling Automation and Intralogistics. Logistics 2020, 4, 22. [CrossRef] 
15. Zafarzadeh, M.; Wiktorsson, M.; Baalsrud Hauge, J. A Systematic Review on Technologies for Data-Driven Production Logistics: Their Role from a Holistic and Value Creation Perspective. Logistics 2021, 5, 24. [CrossRef]

16. Busse, A.; Gerlach, B.; Lengeling, J.C.; Poschmann, P.; Werner, J.; Zarnitz, S. Towards Digital Twins of Multimodal Supply Chains. Logistics 2021, 5, 25. [CrossRef]

17. Watanabe, D.; Kenmochi, T.; Sasa, K. An Analytical Approach for Facility Location for Truck Platooning-A Case Study of an Unmanned Following Truck Platooning System in Japan. Logistics 2021, 5, 27. [CrossRef]

18. Lambrechts, W.; Klaver, J.S.; Koudijzer, L.; Semeijn, J. Human Factors Influencing the Implementation of Cobots in High Volume Distribution Centres. Logistics 2021, 5, 32. [CrossRef] 